\title{
Highlight of Grid-connected PV systems in administrative buildings in Egypt
}

\author{
Dina M.Said, Marwa Mostafa, Kamelia Youssef and Hatem Waheed \\ EgyptERA, Cairo, Egypt \\ dina.said@egyptera.org, marwa.mostafa@egyptera.org, \\ k_energystorm@yahoo.com, hatem.waheed@hotmail.com
}

\begin{abstract}
Solar energy applications are becoming increasingly common in Egypt. The abundant sunshine in Egypt, as well as the increasing competitiveness of solar energy systems includingbut not limited to photovoltaic (PV), - predicts that these technologies could be weighed to be raised in Egypt.
\end{abstract}

PV systems are installed on roof tiles or other parts of building structures to supplement grid utility, reduce electric bills, and provide emergency back-up energy. Moreover, they simultaneously reduce significant amounts of $\mathrm{CO} 2$ emissions. It is foreseen, a number of residential and public buildings in Egypt are using solar power to cut electric utility bills significantly. The approximately payback period to recover the investment costs for PV systems is up to about 5 years. In addition, it is more economical to use PV system than grid utility systems. The two components that determine the total initial price of a gridconnected PV system are the modules and the balance of systems (BOS). The BOS includes different components such as mounting frames, inverters and site- specific installation hardware.

The Government of Egypt (GOE) has endorsed the deployment of PV systems through three approaches. It started with a prime minister decree to install PV projects on one-thousand of the governmental buildings. This was followed by as an initiative called "Shamsk ya Masr", and finally the Feed-in Tariff (FiT) projects.

Following the prime minster decree the Egyptian Electricity Holding Company (EEHC) and its affiliated companies took the lead to install PV systems at the top roof of their administrative buildings and interconnect these systems to the electricity network where the suitable locations have been selected for mounting them. About 90 PV systems have been already mounted with about a capacity of $9 \mathrm{MW}$. On the other hand, "Shamsk ya Masr" has considered energy efficiency (EE) so as to complement the PV systems, which will be installed on administrative buildings. Cost- effective EE measures should be implemented prior to or at the same time as implemented PV program. The amount of electricity that a PV system produces depends on the system type, orientation and the available solar resource. In 2014, the GOE issued the Feed-in Tariff program to further promote RE technologies in general and $\mathrm{PV}$ in particular. Egyptian Electric Utility and Consumer Protection Regulatory Authority (Egypt ERA) has set the regulations, promotion and awareness for PVs. This approach has been applied for administrative buildings as well.

The paper highlights the impact of the previously mentioned mechanisms in deploying PV technologies through small scale projects. It also represents a costbenefit analysis for the installed systems taking into account the measured value for PV parameters $(\mathrm{kWh} / \mathrm{kWp}, \mathrm{PSH})$ and daily load profiles of the selected administrative buildings.

Keywords - photovoltaic (PV), emissions, Feed-in Tariff (FiT), cost- benefit, peak sun hours, grid- tied.

\section{INTRODUCTION}

The Egyptian Electricity Holding Company (EEHC) has sixteen affiliated companies six generation companies (EPCs), nine distribution companies (EDCs) and the Egyptian Electricity Transmission Company (EETC).

Both the Solar Radiation Atlas and the German Aerospace Center estimate Egypt's economically viable solar potential in the range of 74 billion $\mathrm{MWh} /$ year, or many times Egypt's current electricity 
production. The Energy Research Center at Cairo University's Faculty of Engineering estimate that 6 MW of solar PV are currently installed in Egypt. In addition, a $150 \mathrm{MW}$ integrated-solar combined-cycle power plant is in Kureimat, with a solar component of $20 \mathrm{MW}$ is already under operation.

\section{PV SYSTEMS}

Solar panels generate free power from the sun by converting sunlight to electric power with no moving parts, no emissions, and no maintenance. The PV system structure is very flexible. PV modules are the main building blocks, these can be arranged into array to increase electric energy production. Normally additional equipment is necessary in order to transform energy into a useful form or store energy for future use. The resulting system will therefore be determined by the energy needs, or loads, in a particular application.

Solar PV is one of the world's fastest growing renewable energy technologies. This is due to its flexibility in both size and location, ease of installation to both new and retrofit buildings and low operation and maintenance costs. For the PV system to be located on the roof of a building, roof structure must be deigned to accommodate the additional dead loads (static load) of the PV system. The solar panels and racking will add approximately 3 pounds for each square foot of collector area [1].

\section{A. Advantages of solar PV:}

- PV panels provide clean-green energy. During electric production with $\mathrm{PV}$, there is no harmful greenhouse gas emissions, thus PV is environmentally friendly.

- PV panels via photoelectric phenomenon, generate electricity in a direct electricity generation way.

- PV panels have no moving parts, except in case of sun-tracking mechanical bases.

- PV panels are totally silent, producing no noise at all.

- PV panels are easy to install on rooftops.

- Solar energy is energy supplied by nature -it is free and abundant.
- Solar energy can be made available anywhere there is sunlight.

- Solar panels cost is currently on a fast reducing track and expected to continue reducing for the next years.

- Operation and maintenance cost for PV panels are considered to be low, almost negligible.

B. Disadvatnges of solar PV:

- Solar panels efficiency levels are relatively low.

- PV panels require relatively large areas.

- Solar energy panels require additional equipment (inverters) to convert DC to AC in order to be used on the power network.

- Solar energy has intermittency issues, not shining at night but also during daytime there may be cloudy or rainy weather.

- Consequently, intermittency and unpredictability of solar energy makes solar energy panels less reliable a solution.

\section{PV PLANTS PROBLEMS IN EGYPT [2]}

Egypt lies in dusty and very dry weather with limited rainfall $(<10 \mathrm{~mm})$, the results on the PV test park in Cairo:

- Two months dusty module has an energy reduction of $25 \%$.

- One year dusty module has an energy reduction of $35 \%$.

\section{GRID- TIED}

These systems are directly coupled to the electric distribution network and do not require battery storage. Electric energy is either sold or bought from the local electric utility depending on the local energy load patterns and the solar resource variation during the day, this operation mode requires an inverter to convert DC to AC currents. There are many benefits that could be obtained from using grid-tied PV system instead of the traditional stand-alone schemes. These benefits are: 
1. Smaller PV arrays can supply the same load reliably.

2. Takes advantage of the existing electrical infrastructure.

3. Less balance of system (BoS) component are needed

4. Eliminates the need for energy storage

5. Lower capital cost.

\section{- Solar Atlas of Egypt}

Egypt is one of the world's most attractive sites for solar energy thanks to both ample sunlight and proximity to existing and potential energy grids. Solar power uses direct sunlight and must be located in regions with high direct solar radiation. Among the most promising areas of the world are: the SouthWestern United States, Central and South America, Northern and Southern Africa, the Mediterranean countries of Europe, the Middle east and Iran [3].

High intensity of direct solar radiation ranging between $2000-3200 \mathrm{kWh} / \mathrm{m} 2 /$ year from North to South. The sun shine duration ranges between 9-11 h/day from North to South, with very few cloudy days.

Fig .1. represents the map of Egypt's annual average of direct solar radiation.

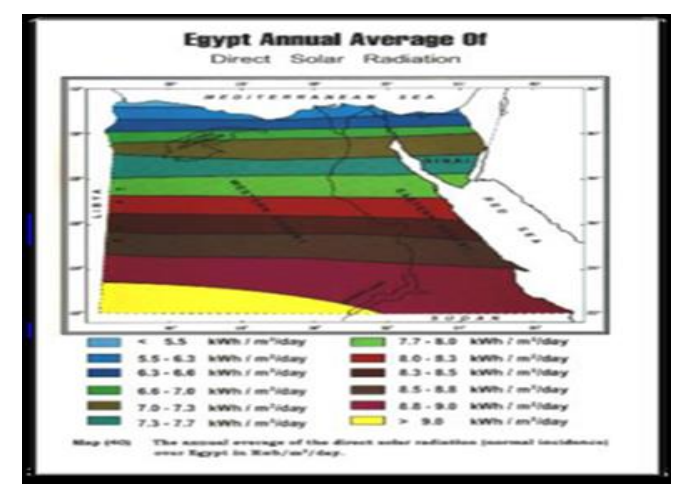

Fig .1. map of Egypt's annual average of direct solar radiation.

Table 1. shows the comparison between direct, diffuse radiation $(\mathrm{kWh} / \mathrm{m} 2 . \mathrm{a})$ in Berlin and Cairo. Horizontal plane radiation in Berlin and Cairo are 1000 and $2000 \mathrm{kWh} / \mathrm{m} 2$.a respectively.
Table 1. Comparison between direct, diffuse radiation $(\mathrm{kWh} / \mathrm{m} 2 . \mathrm{a})$ in Berlin and Cairo

\begin{tabular}{|c|c|c|c|c|}
\hline \multirow{2}{*}{ Month } & \multicolumn{2}{|c|}{ Berlin } & \multicolumn{2}{c|}{ Cairo } \\
\cline { 2 - 5 } Jan & Direct & Diffuse & Direct & Diffuse \\
\hline Feb & 12 & 13 & 67 & 33 \\
\hline Mar & 30 & 41 & 103 & 61 \\
\hline Apr & 42 & 65 & 120 & 72 \\
\hline May & 60 & 90 & 143 & 80 \\
\hline Jun & 64 & 94 & 161 & 71 \\
\hline Jul & 67 & 89 & 163 & 70 \\
\hline Aug & 64 & 70 & 147 & 68 \\
\hline Sep & 40 & 49 & 124 & 57 \\
\hline Oct & 21 & 30 & 99 & 50 \\
\hline Nov & 9 & 13 & 64 & 43 \\
\hline Dec & 3 & 10 & 55 & 36 \\
\hline$\%$ & $42 \%$ & $58 \%$ & $66 \%$ & $34 \%$ \\
\hline
\end{tabular}

Table 2. represents the total monthly solar irradiation $\left[\mathrm{kWh} / \mathrm{m}^{2}\right]$, for this table:

- Horizz.Global solar radiation on horizontal surface in $\mathrm{kWh} / \mathrm{m} 2 /$ day

- Best incline: Solar energy density on south facing flat plate tilted by the latitude angle of the site in $\mathrm{kWh} / \mathrm{m} 2 /$ day

- South: Solar energy density on N-S polar axis and $\mathrm{E}-\mathrm{W}$ tracking in $\mathrm{kWh} / \mathrm{m} 2 /$ day

- East / west: Solar energy density on E-W polar axis and $\mathrm{N}-\mathrm{S}$ tracking in $\mathrm{kWh} / \mathrm{m} 2 /$ day 
Table 2. Total monthly solar irradiation $\left[\mathrm{kWh} / \mathrm{m}^{2}\right]$

"in Marsa - Matroh (Egypt-North)"

\begin{tabular}{|c|c|c|c|c|c|c|c|c|c|c|c|c|}
\hline Orientation & JAN & FEB & MAR & APR & MAY & JUN & JUL & AUG & SEP & OCT & NOV & DEC \\
\hline Horizz. & 3.1 & 3.97 & 5.33 & 6.61 & 7.37 & 8.01 & 7.98 & 7.37 & 6.3 & 4.73 & 3.51 & 2.92 \\
\hline South & 5.27 & 6.32 & 7.17 & 8.41 & 8.89 & 9.27 & 9.33 & 9.08 & 8.16 & 6.69 & 5.34 & 4.7 \\
\hline East/West & 4.9 & 5.49 & 5.89 & 6.81 & 7.35 & 7.81 & 7.73 & 7.13 & 6.34 & 5.56 & 4.84 & 4.46 \\
\hline Best incline & 4.54 & 5.3 & 5.83 & 6.54 & 6.54 & 6.52 & 6.6 & 6.63 & 6.29 & 5.45 & 4.54 & 4.08 \\
\hline
\end{tabular}

\section{MONTIROING SYSTEM}

A monitoring system is a common component in PV systems. Monitoring allows tracking of solar system performance over the life of the system and makes it easy to identify systems that perform below expectation and may be in need maintenance. Monitoring systems requires an internet connection in the room that contains the inverter.

The monitoring system was designed to meet guideline of standard IEC 61724 and within the framework of the International Energy Agency Photovoltaic Power System (IEA PVPS) Program. For the general data acquisition, a multi- function increasing device measures the different parameters, such as: KWP /month, kWh/day, kWh/month, ...etc.

Egypt's geographic location provides a generous solar resource that should be exploited to its maximum potential. The use of PV technology could allow the local community to take advantage of this resource without sacrificing land resources by using the building rooftops as energy collection fields. Using roof areas is more economical.

\section{PERFORMANCE INDICES OF PV SYSTEMS}

There are many indices for assessing PV systems performance

\section{Peak Sun Hours ( PSH)}

This is the equivalent number of hours per day when solar irradiance average $1000 \mathrm{~W} / \mathrm{m} 2$, or it refers to the solar irradiance which a particular location would receive if the sun was shining at its maximum value for a certain number of hours. Fig .2. represents this definition.

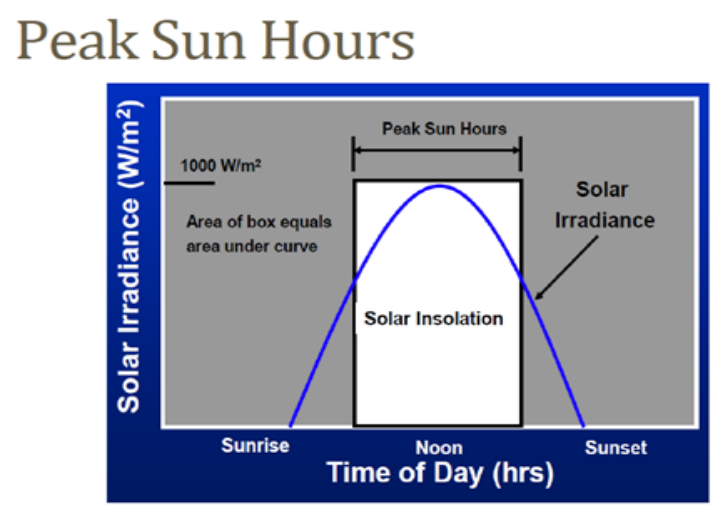

Fig .2. Definition of PHS

PHS is calculated based on the following equation:

PHS $\left(\frac{h r s}{\text { day }}\right)=\frac{\text { Avg.Daily Irradiation }\left(k W h / m^{2} \cdot \text { day }\right)}{\text { Peak Sun }\left(1 \frac{k W}{m^{2}}\right)}$

By using the monitoring data for $90 \mathrm{PV}$ systems related to EDCs according to geographical location for each EDC. The calculation of PHS were carried out and presented in Table (3).

The result is: av. PHS for 90 PV located in different locations in Egypt, are between 4 and $7.7 \mathrm{hr} / \mathrm{d}$.

Table 3. The PSH for EDCs

\begin{tabular}{|c|c|c|}
\hline Company & $\begin{array}{c}\text { Range of PSH } \\
(\mathrm{hr} / \mathrm{d})\end{array}$ & $\begin{array}{c}\text { Av. PSH } \\
(\mathrm{hr} / \mathrm{d})\end{array}$ \\
\hline EDC 1 & $3.9-7.2$ & 5.3 \\
\hline EDC 2 & 4 & 4 \\
\hline EDC 3 & $2.7-12.4$ & 5.1 \\
\hline EDC 4 & $5.5-6.4$ & 4.1 \\
\hline EDC 5 & $3.6-7.1$ & 5.1 \\
\hline EDC 6 & $2.9-7.1$ & 4.4 \\
\hline EDC 7 & $3.9-6.2$ & 4.7 \\
\hline EDC 8 & $3.7-6.8$ & 7.7 \\
\hline EDC 9 & $3.9-6.5$ & 5.2 \\
\hline
\end{tabular}




\section{Performance ratio (PR)}

The PR is the ratio of PV energy actually used to the energy theoretically available. PR is calculated based on the following equation

$\mathrm{PR}=\mathrm{Yf} / \mathrm{Yr}$

Where:

$\mathrm{Yf}$ is final system yield $=\mathrm{Epv} / \mathrm{Po}$

in $(\mathrm{kWh} / \mathrm{KWp} . \mathrm{d})$ or $(\mathrm{hr} / \mathrm{d})$

$\mathrm{Yr}$ is reference yield $=\mathrm{Hi} / \mathrm{GSTC}$

in $(\mathrm{kWh} / \mathrm{KWp} . \mathrm{d})$ or $(\mathrm{hr} / \mathrm{d})$

Table 4. The PR values for PV systems in Egypt

\begin{tabular}{|c|c|c|c|}
\hline Company & $\begin{array}{c}\mathrm{Yr} \\
\text { Range of global } \\
\text { solar radiation } \\
(\mathrm{kWh} / \mathrm{m} 2 . \mathrm{d})(\mathrm{Hi})\end{array}$ & $\begin{array}{c}\mathrm{Yf} \\
(\mathrm{av} .) \\
\mathrm{kWh} / \mathrm{k} \\
\mathrm{Wp.d}\end{array}$ & $\mathrm{PR}$ \\
\hline EDC 1 & $<5.4$ & 5.3 & 0.98 \\
\hline EDC 2 & $5.4-5.8$ & 4 & $0.72-0.74$ \\
\hline EDC 3 & $5.6-5.8$ & 5.1 & $0.88-0.91$ \\
\hline EDC 4 & $5.4-5.6$ & 4.1 & $0.73-0.76$ \\
\hline EDC 5 & $5.8-6.0$ & 5.1 & $0.85-0.9$ \\
\hline EDC 6 & $5.8-6.0$ & 4.4 & $0.73-0.76$ \\
\hline EDC 7 & $5.8-6.0$ & 4.7 & $0.81-0.84$ \\
\hline EDC 8 & $6.4-6.6$ & 4.7 & $0.71-0.73$ \\
\hline EDC 9 & $6.8-7.1$ & 5.2 & $0.73-0.77$ \\
\hline
\end{tabular}

Table 4. shows the PR values for some PV system according to their locations indicated by each DC.

Previously, companies used to guarantee the specific yield of a PV plant

- Typically required by uninformed clients.

- Not possible due to fluctuations in weather conditions.

- Ends in very conservative calculations to minimize risk.

Nowadays, PV clients are more informed

- Request PR guarantees

Typical PR ranges 70 - $85 \%$

Independent testing body typically conducts audits.

\section{- Factors affecting PR:}

- Irradiance losses.

Modules are rated at STC.

- Temperature losses.

Modules 25 degrees Celsius.
- Module mismatch.

Due to + or - tolerance range in module rating .

- Cabling losses.

- Transformer losses.

- Inverter losses.

- Soiling losses.

- Shading losses.

\section{BENEFIT- COST ANALYSIS}

1. Benefit-cost analysis:

When the benefits of a project can be valued, they are discounted and aggregated, and compared with the associated aggregate costs over the lifetime of a project. Comparison between project costs and benefits can be conducted in the following ways:

- Benefit-cost ratio: compares the total discounted benefits of electrification with total discounted costs, as a ratio, and provides an indication of the scale of return on the investment. This is done by examining the ratio of the present value of benefits to the present value of costs. If the ratio of benefits to costs is greater than one, the project can be viewed as desirable from an economic point of view.

2. Economic Benefits and Costs:

Investment evaluations of energy systems generally include an assessment of the projected benefits compared to the estimated costs of the system. The direct financial benefit of a BIPV system is primarily the value of energy generated.

These benefits and the direct economic costs of a BIPV may be viewed as:

- Projected Benefits = Value of Electricity Generated

- Estimated Costs =

Capital Costs + Periodic Costs + Replacement Costs

Quantitative analysis is a tool that facilitates ranking and choosing among investment alternatives. As such, quantitative procedures appear to be straightforward. However, numerous factors influence comparative evaluations. A building owner's economic expectations about future interest rates, inflation, and fuel costs directly affect investment decisions, as can utility interface requirements, environmental regulations, and tax incentives. 
The Egyptian government started installing PV projects on one-thousand of the governmental buildings, which was followed by as an initiative called "Shamsk ya Masr", then the Feed-in Tariff (FiT) projects were launched.

\section{FIT}

Egypt faces a major challenge in generating electricity from its primary energy resources, especially oil and natural gas that contribute to $97 \%$ of the total energy resources. Studies show that even though Egypt has reasonable reserve of gas and oil, it is likely that it will face severe shortage in satisfying its electricity demand due to rapid growth in demand and the increase of oil and gas extraction costs [4]. Noticing this problem, Egypt has consequently pursued several mechanisms for deploying Renewable Energy (RE) technologies and integrating them to the Egyptian electricity systems.

Unfortunately, lots of barriers have impeded Egypt from achieving any of its electricity generation targets; particularly financial and regulatory barriers. Feed-in tariff (FiT) is one of the mechanisms that has been adequately studied but was never recognized as a possible solution to the deployment of RE due to existing electricity tariff subsidies. Moreover, the huge political transition that started in 2011 has led to deteriorating the economic and financial position of the country. The global economic slowdown, started in 2008, caused a decline in Foreign Direct Investment, the international reserves also fell sharply by that time, and its creditworthiness has been undermined as reflected by lowering of the international ratings assigned to Egypt. Certainly, this is considered a typical unhealthy environment to attract investments or even to maintain the existing ones. Recently, the government of Egypt (GoE) has launched several national programs in order to regain its economic health.

On September 2014, Egypt has announced its ambitious FiT program for deploying $4300 \mathrm{MW}$ of wind and solar energy in a 2-years' time. It is believed that the program as designed in this way would overcome most of the barriers that have hindered the RE market in Egypt.

FiT planning program for Egypt includes the early provision for setting the RE target for Egypt at larger and the capacity cap for the FiT program in particular.

\section{RE-FiT Policy Making}

Several studies were conducted to assess the energy situation in Egypt. These studies have indicated that retaining balance between oil and natural gas production and their usage within three (3) years can be achieved after overcoming the economic challenges facing the oil and natural gas sector. However, it is expected that Egypt will be a net importer of oil and natural gas within ten (10) years from the start of the third decade of this century. This situation represents an additional challenge for the Egyptian economy which will become more vulnerable to the price fluctuations in the international energy markets, which can't be predicted or controlled. Therefore, there has to be diversity in the energy resources so as to maximize the benefits of using local RE resources which are characterized by sustainability and stable prices. [5]

\section{A. Setting the Target}

The starting point for RE policy making is usually the definition of targets in terms of installed capacity or minimum shares in the country's electricity production. In Feb. 2008, the Supreme Council of Energy has set a target to have a $20 \%$ of the total generated electricity to be from RE resources by the 2020 . Wind energy was been given the priority such that it would represent $12 \%$ of the total target (equivalent to 7200 MW). Hydro power will provide $6 \%$ and the remaining $2 \%$ will come from other RE resources including solar and biomass energies. In July 2012, the Cabinet approved the Egyptian Solar Energy target with a total installed capacity of $3500 \mathrm{MW}$ by the year 2027. It includes $2800 \mathrm{MW}$ from Concentrated Solar Power (CSP); in addition to $700 \mathrm{MW}$ from Photovoltaic (PV). The private sector should participate with $67 \%$ of the mentioned capacities, while the governmental projects share, represented by New and Renewable Energy Authority (NREA), will be 33\%.[6]

\section{B. Defining the Mechanisms}

Once targets have been defined the choice of appropriate policy instruments/mechanisms should realize their achievement. They considerably vary in their design and conception. Some of them stimulate the supply of renewable electricity, while others directly affect the demand. Furthermore, support schemes can be distinguished according to the chosen instrument. 
All of the above mentioned mechanisms are currently in place in Egypt. State owned projects which are carried out by NREA, the BOO projects which are carried out by the Egyptian Electric Transmission Company (EETC) through tendering process, and the bilateral market of RE where Power Producers (PPs) that get into bilateral contracts with their own customers, are all mechanisms that Egypt has undertaken for quite long time. However, the achievements that were expected from these mechanisms have never been satisfied. A deep insight into the reasons behind such shortcomings is due to (but not limited to); the GoE could hardly manage the sovereign risks causing prolonged delay in the first $250 \mathrm{MW} \mathrm{BOO}$ wind projects, the heavily subsided tariffs and absence of quota system hurdles the bilateral market of RE so that PPs to could hardly get into contracts with direct customers, and last but not least, failure to realize the RE Fund. Accordingly, a concrete design for a FiT system taking into consideration the current economic, financial, regulatory and legal barriers became essential. [7]

\section{Design of Feed-in tariff program}

In October 2014, the FiT program for (PV - Wind) projects has been announced according to a prime minister decree. A total capacity cap of $4300 \mathrm{MW}$ is to be achieved over the first regulatory period of applying the FiT. This target includes $300 \mathrm{MW}$ for small PV projects below $500 \mathrm{~kW}, 2000 \mathrm{MW}$ for medium size PV projects which range from $500 \mathrm{~kW}$ up to $50 \mathrm{MW}$ and the remaining $2000 \mathrm{MW}$ is from wind projects with capacities ranging from $20 \mathrm{MW}$ up to $50 \mathrm{MW}$. The first regulatory period starts from the day of announcing the FiT (i.e. October 2014) and ends if either the capacity cap is reached or a two years period is passed, whichever happens first. The EETC or the electricity distribution companies are committed to purchase the produced electricity from RE power plants at the prices announced by the Cabinet over the duration of the PPAs which is 20 years for wind and 25 years for PV.

Four basic pillars should be in place to support the design of the FiT program. These are the legal, regulatory, contractual frameworks and the tariff structure. Each of these four pillars will be discussed in this section. [8]

\section{CONCLUSION}

Within Egypt power Strategic plan, the power sector strategy is depending on the diversification and expansion of energy resources, and rational use of conventional energy resources.

Moreover the solar Atlas indicates that Egypt is one of the sun belt countries endowed with high intensity of direct solar radiation ranging between 2000-3200 $\mathrm{kWh} / \mathrm{m} 2 /$ year and sunshine duration from 9-11 hours per day which offers opportunities of investing in Solar energy projects.

The Egyptian Electricity Holding Company is cooperating with the New and Renewable Energy authority through the following:

- Generation planning taking into consideration the contribution of the renewable energy.

- Network planning to ensure safe evacuation of the generated energy from the renewable energy projects.

- The Egyptian Electricity Transmission Company is tendering competitive biddings for the construction of renewable energy power plants through BOO (Build, Own and operate) model at predetermined sites.

The endowment of Egypt with these renewable resources is offering a great opportunity to exchange "Clean Energy" through the electrical interconnection with neighboring countries.

The Egyptian Electricity Holding Company and its affiliated companies have taken the initiative to install solar Photo Voltaic (PV) systems at the top roof of their administrative buildings and interconnect these systems to the Unified Power System where the suitable locations have been selected for mounting them $90 \%$ solar PV systems have been contracted with a total capacity of $9 \mathrm{MW}$.

The Monitoring systems are good tools to evaluate the performance for the PV plants.

The results are:

- av. $\mathrm{PSH}$ in range 4: $7.7 \mathrm{hr} / \mathrm{d}$

- $P R$ in range 0.71: 0.98 which is in the recommended range. 
FiT is considered a solution to major challenges hindering the development of RE market in Egypt, although being a challenge in itself. The learning process that preceded the design of the FiT program, started at a time when this approach was not foreseen at any level of decision making in the GoE.

However it was essential to gain the adequate knowledge of FiT design at large, and for the Egyptian case in specific. For solar energy, the tariff was categorized between different sizes of projects in order to match with the different categories of customers (individuals, commercial and large investors). Also, the GoE has provided soft loans for individuals and small customers. When it came to implementation, the design was accurately fine-tuned; first to the economic updates, second to overcome various barriers which have been ingrained in the existing corporate's culture. Moreover, the GoE has mandated the electricity companies to carry out the required procedures on behalf of the small customers in order to facilitate the process of acquiring the loans. Also, a one-stop-shop entity to facilitate the overwhelming official procedures was established.

Finally, it is worth mentioning that lack of interest in a FiT program from the GOE has stopped it for years, nevertheless the commitments which GoE has recently declared were the backbone for supporting the FiT today. These include; issuance of the RE law that among its articles has approved the quota system that reduces the financial burden on the electricity sector due to the feed-in tariff, availing state lands for investors, providing sovereign guarantees for large projects, offering low interest loans for small projects, and providing finance for upgrading the transmission and distribution infrastructure.

\section{REFERENCES}

[1] www.solar-rating.org

[2] The First Grid connected PV power plant in Egypt Arab Organization for Industrialization.

[3] IEC 61724:1998(E): Photovoltaic system performance monitoring - Guidelines for measurement, data exchange and analysis.

[4] Draft Egypt Energy Strategy 2035 (2015): "to be published"

[5] Design of a Feed-In Tariff Structure and a Contractual Relationship Template for Wind Power in Egypt (2011): "internal document"

[6] Po Annual Report, (2012/2013): New and Renewable Energy Authority http://www.nrea.gov.eg/annual\%20report/Annual $\underline{\text { Report } 20122013 \text { eng.pdf }}$

[7] Combined Renewable Energy Master Plan for EGYPT (2009 - 2011): "internal document"

[8] Renewable Energy - Feed-in Tariff Projects Regulations (2014): Egyptian Electric Utility and Consumer Protection Regulatory Agency http://egyptera.org/Downloads/taka\%20gdida/Dow nload\%20Renewable\%20Energy\%20Feedin\%20Tariff\%20Regulations.pdf 